ISSN 2524-2369 (Print)

ISSN 2524-2377 (Online)

\title{
ЭК АНОМІКА
}

ECONOMICS

УДК 330.13:330.15:630*8

https://doi. org/10.29235/2524-2369-2022-67-1-118-124

Поступила в редакцию 09.10.2020

Received 09.10.2020

\section{Т. В. Каштелян}

Белорусский государственный технологический университет, Минск, Беларусь

\section{ИННОВАЦИОННО-СОЦИАЛЬНО-ЭКОЛОГИЧЕСКАЯ ТРАНСФОРМАЦИЯ ЛЕСНОГО СЕКТОРА БЕЛАРУСИ В КОНТЕКСТЕ ЗАКОНОМЕРНОСТЕЙ РЕНТНЫХ ОТНОШЕНИЙ ХОЗЯЙСТВЕННЫХ СИСТЕМ}

\begin{abstract}
Аннотация. Методологической базой исследования инновационно-социально-экологической трансформации лесного сектора Беларуси явилась фундаментальная теория ренты. Цель работы - представить современные закономерности развития рентных отношений хозяйственных систем и необходимость их учета в экономической деятельности лесного сектора, наметить пути практического применения сложного дифференцированного знания о ренте в аспекте активных и пассивных (фоновых) поведенческих паттернов инновационно-социально-экологического развития национальной экономики.

Рассмотрены особенности и направления развития рентных отношений, основанные на анализе их институциональной организации в различных сферах экономической деятельности. Обоснованы компоненты структурно-логической модели единого институционального социо-экосистемно-экономического пространства, аргументирована потребность их встраивания в рентные отношения лесного сектора с учетом постановки целей инновационного развития. Обозначается роль импакт-финансирования в системе «обратных связей» лесного сектора как составляющей институциональной платформы устойчивого развития. Предлагается система средств-ценностей образования лесной ренты. Раскрывается содержание инновационно-социально-экологической трансформации лесного сектора Беларуси, характеризующейся созданием собственности на основе устойчивой управляемой стоимости ренты, требующей увязки разнообразных интересов и управленческих решений с инновационным рентным форматом экономических отношений через создание ресурсов и собственности.

Ключевые слова: рентные отношения, рентообразование, лесной сектор, инновации, развитие, социальная трансформация, экологические институты, экономические и социальные эффекты

Для цитирования: Каштелян, Т. В. Инновационно-социально-экологическая трансформация лесного сектора Беларуси в контексте закономерностей рентных отношений хозяйственных систем / Т. В. Каштелян // Вес. Нац. акад. навук Беларусі. Сер. гуманітар. навук. - 2022. - Т. 67, № 1. - С. 118-124. https://doi. org/ 10.29235/2524-2369-2022-67-1-118-124
\end{abstract}

Taisiya V. Kashtelyan

Belarusian State Technological University, Minsk, Belarus

\section{INNOVATIVE SOCIAL AND ENVIRONMENTAL TRANSFORMATION OF THE FOREST SECTOR OF BELARUS IN THE CONTEXT OF MODERN THEORY OF RENT RELATIONS IN ECONOMY}

Abstract. Fundamental theory of rent is a methodological framework of a research of innovative social and environmental transformation of forest sector of Belarus. The purpose of the work was to highlight an importance of patterns of rent-based economies and the need for them to be accommodated in the economic relations of the forest sector, as well as to identify the operational applications of complex and differentiated knowledge of rents in an aspect of active and passive (monitoring, associative) behavioral patterns.

Analysis of the institutional organization of production is presented; the features and directions of development of rental relations are considered. Components of the structural and logical model of single institutional socio-ecosystem space that are embedded in the rental relations of society; are justified by the forestry practice. The role of impact investment and a "feedback" loop of the forestry sector as an institutional platform for sustainable development is outlined. The content of the innovative-socio-ecological transformation of the forestry sector in Belarus characterized by posing questions on property creation covered by stable and manageable value of rent, requiring the linking of various interests and management decisions with the rental format of economic relations as a mechanism for the transition to sustainable development through resources and property, is revealed.

(C) Каштелян Т. В., 2022 
Keywords: rental relations, rent formation, forest sector, innovation, development, social transformation, impact investing, ecological institute, economic and social effects

For citation: Kashtelyan T. V. Innovative social and environmental transformation of the forest sector of Belarus in the context of modern theory of rent relations in economy. Vestsi Natsyyanal'nai akademii navuk Belarusi. Seryia humanitarnykh navuk $=$ Proceedings of the National Academy of Sciences of Belarus. Humanitarian Series, 2022, vol. 67, no. 1, pp. 118-124 (in Russian). https://doi.org/10.29235/2524-2369-2022-67-1-118-124

Введение. Беларусь - одна из стран, которая не остается в стороне от проблем устойчивого эколого-экономического развития и «зеленого» роста. Ряд аспектов внедрения стандартов охраны окружающей среды в производство и финансирование эколого-ориентированных мероприятий дает основание говорить об институциональном совершенствовании экономических отношений и хозяйственного порядка. Осуществляется обсуждение вопросов трансформации видов экономической деятельности, связанных с потреблением возобновляемых природных ресурсов, в частности лесных. Однако система рентных отношений лесного сектора в едином дискурсе теоретического контекста несколько умаляется, в то время как она обладает потенциалом повышения эффективности и улучшения положения экономики в условиях усиленной глобальной конкурентной борьбы за средства к существованию, развития сложных «зеленых» рынков, интеллектуализации общества, демократизации собственности и др.

Устойчивое развитие на базе земель лесного фонда предполагает решение разноплановых, разнонаправленных проблем экономического роста с одновременным сохранением качества среды обитания и расширением масштабов «зеленого» финансирования. Институциональные преобразования и решения, связанные с финансами и экологическим регулированием, должны многопланово трансформировать социо-эколого-экономическую среду, обеспечивая «прозрачность» выгод природопользования, стимулы и эффективное развитие на базе стоимостных критериев, связанных с проявлениями ренты. Содержание и назначение финансовых средств участников современных рентных отношений лесного сектора подлежат переосмыслению в аспекте достижения целей инновационного развития, которые представляются и с позиций инфраструктурных потребностей, и в аспектах сложных социально-экологических отношений «зеленого» роста. Имеются дискуссии по усилению процессов коммерциализации природных благ и их последствий, широко рассматриваются вопросы присвоения материально-вещественных ценностей и позиционирования услуг лесных экосистем.

Цель исследования и основные результаты. Цель работы - представить закономерности развития рентных отношений хозяйственных систем и необходимость их учета в экономической деятельности лесного сектора, наметить пути практического применения сложного дифференцированного знания о ренте в аспекте активных и пассивных (фоновых) поведенческих паттернов инновационно-социально-экологического развития экономики. Методологическая база - фундаментальная теория ренты, в которой отображается, с одной стороны, проблема существования ограниченных факторов общественного производства (входные параметры) и их доходности, с другой - деятельность по осуществлению трансфертов, потребляемых экономическими агентами в связи с изъятием, преобразованием, сохранением и восстановлением разнообразных природно-ресурсных (продуктовых, инфраструктурных) благ и экосистемных услуг.

Содержательный аспект рентных отношений в условиях бурных технологических изменений и выстраивания структуры современного постиндустриального общества считаем возможным исследовать через совокупность свойств современных экономических процессов, учитывая институциональные новшества современной теории и практики хозяйствования, включая социально-экологические. Рассмотрение термина «рента» в экономике предполагает не просто проведение практических оценочных расчетов «излишков» доходов, но и понимание эволюционного перехода экономических отношений от «земельной ренты» к расширенной концепции природно-ресурсного и экологического капиталов (лесного в том числе). Именно система «воспроизводство» позволила утвердить стоимость ренты как «излишка» или той добавленной стоимости, которую может присваивать собственник. Учитывая такую особенность институциональной «окраски» рентных отношений, нами выделен общий пошаговый контент, в котором функционирует триада «воспроизводство - адаптация - развитие» [1]. 
Воспроизводство в данной логической последовательности означает позиционирование стоимости как момент проявления возмещения потраченных активов и ресурсов, но особые проявления ренты можно наблюдать в системе «адаптация», когда стоимость обретает приспособляемость к внутренним обстоятельствам многоотраслевой национальной экономической деятельности и внешним условиям. Экономическая реальность достаточно быстро меняется. Воспроизводственный подход к организации общественного производства стал испытывать на себе значительные издержки «провалов» рынка и неспособности экономических процессов обеспечивать новое качество трансформации общества, связанного с достижением глобального благосостояния. В частности, за период 2016-2018 гг. рейтинг Беларуси, оцениваемый по индексу экологической эффективности, заметно снизился (от 35-го до 44-го места), причем доля отрицательного влияния динамики по совокупному показателю «экологическое здоровье» оказалась в два раза меньше, чем негативное воздействие комплексного критерия «жизнеспособность экосистем» [2]. На наш взгляд, такая ситуация является одним из следствий несоответствия лесной ренты ее содержанию и требованиям учета закономерностей прогрессивных рентных отношений, «играющих новыми красками» в современном инновационном, сетевом, цифровом обществе.

Исследования ренты и рентных отношений представлены довольно широким перечнем работ. Многие используют понятие «ренты» как отношение между пользователем («добытчиком» или тем, кто зарабатывает доход) и владельцем прав на использование ограниченного ресурса или применение его в целях извлечения предпринимательской прибыли. Однако акцентирование на этом распределительном моменте экономической реальности превратилось в некий «приоритетный» фактор выражения требований государства к доходности моделей осуществления бизнес-процессов и поведения субъектов в сложной экономической среде, обеспечивающей накопление природно-ресурсного и экологического капиталов (через модернизационный потенциал ресурсов, финансовый менеджмент и инвестирование). В то же время, как показал анализ [2], постановка инновационных целей развития национальной экономики требует корректировок практики и стимулов для обеспечения высоких результатов работы с позиций крупномасштабных инфраструктурных проектов, связанных с экосферой в частности.

На рубеже 2000-х гг. большое значение стало придаваться правилам и нормам, которым должны следовать субъекты хозяйствования, организуя производство в окружающей среде. Существуют как теоретические, так и эмпирические доказательства того, что экономические отношения претерпели так называемое смещение центров, формирующих добавленную стоимость, при этом классические схемы рентных отношений видоизменились, стали источниками социальной напряженности и конфликтов [3]. С начала нынешнего тысячелетия исследования развивались в направлениях формирования собственности, фиксирующей материальное и нематериальное производство природных благ. Основными трудностями, с которыми столкнулись экономисты постсоветского экономического пространства, - это зависимость от искажений рыночного механизма (несовершенств рынков, ограничивающих правил, необоснованных информационных «фильтров», методов управления, которые привлекали внимание, прежде всего, с позиций поляризации обобществленной и частной форм собственности).

Сегодня, в условиях высокого влияния на экономику информационных технологий, приходится констатировать, что большую роль играют «вычислительные» ресурсы развития хозяйственных систем. В качестве факторов улучшения организации экономического пространства указываются «киберфизические системы» и медиаплатформы «Земля», другие элементы экономики знаний, управляемой большими данными, поддерживаемыми совокупными экономическими агентами - домашними хозяйствами, собственниками, инвесторами и др. При этом все указанные группы «привязки» к созданию так называемого «символического» производства природы являются потребителями экономических и экологических благ, осуществляют интеракции и трансакции в биоэкономической системе, обладающей взаимодействием биофизических, социальных, институциональных и других факторов. Уязвимость систем наращивания стоимости в триаде «воспроизводство - адаптация - развитие» лесного сектора Беларуси, несмотря на широкое применение геоинформационных технологий для учета ресурсов, связана с условиями ограниченного финансового потока от пользователя к титульному владельцу, не обладающему, по сути, возможностями оптимизации растрачиваемых средств. «Символическое» производство 
природы (в условиях переданного дохода от титульного собственника государственным учреждениям, что оценивается нами только положительно) пока не привело к существенному увеличению предложений по его совершенствованию и к решениям проблем эффективно функционирующих практик менеджмента.

Рентные отношения современности как отношения, связанные с формированием и использованием земельной недвижимости и ресурсов, ассоциируются с интенсивностью приносимого дохода и обновлением природного капитала. С позиций принятия управленческих решений для инновационного развития (накопления финансовых средств) выделим широко применяемые способы получения ренты в аспектах экономического и социально-экологического дискурса: 1) через учет потребностей населения в системе конвертации земельных (лесных) ресурсов по активному направлению деятельности (спросу на товары и услуги промежуточного и конечного потребления); 2) посредством невозмещения затрат загрязняющего и расточительного (неэкономного) функционирования экономических агентов. Суть последнего истощающего природу накопления капитала заключается в нерациональной эксплуатации ресурсов и объектов земельной недвижимости. Для субъектов хозяйствования это означает отсутствие необходимого и достаточного уровня вкладов в воспроизводство ресурсов, нанесение урона окружающей среде, истощение плодородия почв, водных систем и др. С позиций рентных отношений и формирования экономики инновационного типа для институционализации решения экологических задач и недопущения плохого менеджмента требуется применение различных и многоуровневых знаний о сетевых благах современного общества, которые опосредуют отношения между социумом и окружающей средой в определенных исторических и географических условиях.

В своих исследованиях ренты как термина, используемого в современном мире глобализации и цифровизации, О. Фрейссе [5] указывает, что факт о принятии видимости «земельной» ренты ничего не говорит о механизмах создания стоимости или присвоения, составляющих содержание ренты. Интересны выводы данного автора об абсолютной ренте как о «дани», возникающей в ситуации, когда одна часть общества требует от другой отдачи за само право жить на земле. Таким образом, О. Фрейссе акцентирует внимание на исключительно политических характеристиках абсолютной ренты. Он затрагивает и сферу природопользования, однако не конкретизирует задачи и содержание регулирования земельных отношений.

Процесс создания ренты в интернет-среде определяется как совместная работа пользователей и поставщиков услуг. Однако пользователи пока не имеют возможностей запрашивать заработную плату за время, проведенное в сети [4]. Эта характеристика рентных отношений, данная О. Фрейссе, является сходной с состоянием непрекращающегося конфликта между собственниками капитала и труда. Инкорпорирование стоимости ренты с ее распределительными моментами «общественного блага» и «биополитической» конкретикой затраченного времени на то, чтобы эксплуатировать предоставленное виртуальное пространство, позволяет расширить понимание возможностей хозяйствования на базе лесных земель от продуктово-энергетических цепей добавленной стоимости до атрибутов систем природных комплексов. К подобным выводам приходят и другие исследователи, наделяя рентные отношения эксплуатационно-пространственным смыслом и монопольными правами использования объектов недвижимости [5].

Экологические институции хозяйственных систем рассматриваются сегодня сквозь призму формирования «вкладов Природы» и социально-экологической экономии «второго контура» Д. Харви [5], что актуально для функционирования отечественной государственной собственности (хозяйствования на государственных лесных землях). Контекст рентных отношений «обратной связи» не лишает нас возможностей рассмотрения присвоения стоимости, проистекающей из прав власти и земельных прав в частности, в то же время он допускает трактовку ренты как финансовой основы развития социо-эколого-экономической среды государства, зависящей от институционального разнообразия хозяйственных практик.

Рентные отношения стали заметным явлением обобществленной собственности, в частности интеллектуальных ресурсов. Это отметили авторы публикации [6], посвященной современным экономическим отношениям в аспектах ухода от форм частной интеллектуальной ренты к большим данным публичного характера и позиционирования прав на них через институционализацию форм и условий коммерциализации инноваций. Результативность деятельности по- 
тенциальных «добытчиков» ренты «достигает своей ценности и доказывает свое использование только в условиях строгой взаимозависимости с непрерывным расширением данных, являющихся общественным достоянием» [6]. Так, интерпретируя инновационный поворот в сфере доступа к интеллектуальным ресурсам (на примере биоинформатики), учеными выдвинута идея импульсов эффективности экономики - «инновационный институциональный источник вариаций и экспериментов», который позволил на основе роста частного и корпоративного рынка с его «захватами» ренты эволюционировать системе «общественного благосостояния благодаря распределенному пространству ценностей» [6]. В любом случае интеллектуальная рента объективно реализует инновационное развитие. Но вместе с тем следует признать позицию, что наличие ренты глобального (планетарного) пространства - это система прав и элементов, которые имеют завуалированные ценности, их реализация на рынки возможна в ситуации де-юре на базе партнерских отношений частных субъектов, корпораций и государства.

Лесная рента Беларуси не отрицает прав создания общественного достояния, в то же время она не «улавливает» совладельческую функцию работников лесного хозяйства, которые обязаны обладать не просто базами больших данных для осуществления мониторинга и реальных хозяйственных практик, но и «сетью» обмена предоставляемых услуг для обеспечения четких ориентиров воспроизводственных процессов в аспектах адаптации и развития [1]. «Распыленные» права и кластеры пространственных ценностей, генерируемые деятельностью работников лесного хозяйства, в системе стоимостного обмена национальной экономики институционально организованы по принципу «производственной функции», ориентированной на неинтегративные цели. Обрамление ренты (экономической) концептуальными положениями экологической ее стоимости, ассоциируемой как с правовыми элементами планетарных границ менеджмента, так и с коллективным потреблением общественных (сетевых) благ при их индивидуальном и корпоративном производстве, выводит нас на так называемую «накопительную» емкость добавленной стоимости во имя будущего. Импакт-инвестирование - это финансовые ресурсы во имя обновления (накопления и рационального использования амортизационного фонда) природной среды. На наш взгляд, их функционирование можно связать и с системой страхования экономической деятельности, основанной на перспективах получения ресурсов в будущем.

Импакт-инвестирование стоит рассматривать как неотъемлемую часть владения активами и ресурсами. Для нашей страны и ее лесного сектора вполне приемлемыми должны стать собственные модели инновационного развития, направленные на максимально возможный отказ от ненужного перераспределения финансов, в которых рентные отношения будут выстраиваться по принципу новых типов социо-эколого-экономических отношений (связи распределения с производством, государственно-частного партнерства и др.). Речь идет о движении по вектору самоорганизации систем хозяйствования, что в конечном итоге позволит активизировать барьерную функцию - противостояния финансово-экономическому капиталу в его стремлении «инвестировать» в «упущенные выгоды», т. е. применять не эколого-ориентированные технологии. Для институциализации инновационно-социально-экологического развития лесного сектора Беларуси следует учитывать значимость лесовосстановительных процессов, многообразие устойчивого лесопользования и эколого-ориентированного развития национальной экономики в целом, осуществляемого с помощью «раздачи» прав и их создания в биофизическом и экономическом смыслах (что идентифицируется и в киберпространстве).

Для отрасли лесного хозяйства как сферы применения технологии эколого-ландшафтного обустройства территории земель государственного лесного фонда в широком рентном формате целесообразно прибегнуть к ресурсо-созидающим и эколого-инклюзивным средствам инноватизации экономических процессов и в первую очередь рентных отношений [7; 8]. С этих позиций мы можем обозначить современную систему средств-ценностей рентообразования (рисунок).

Схематически существование институционального социально-эколого-экономического пространства с точки зрения рантье предполагает мониторинг средств достижения ценностных ориентаций устойчивого развития, но «обратные связи» социально-экологических эффектов (улучшенной экоструктуры пространства, эколого-ландшафтные ценности) предполагают центральное позиционирование ценовых способов извлечения добавленной стоимости, создаваемых 


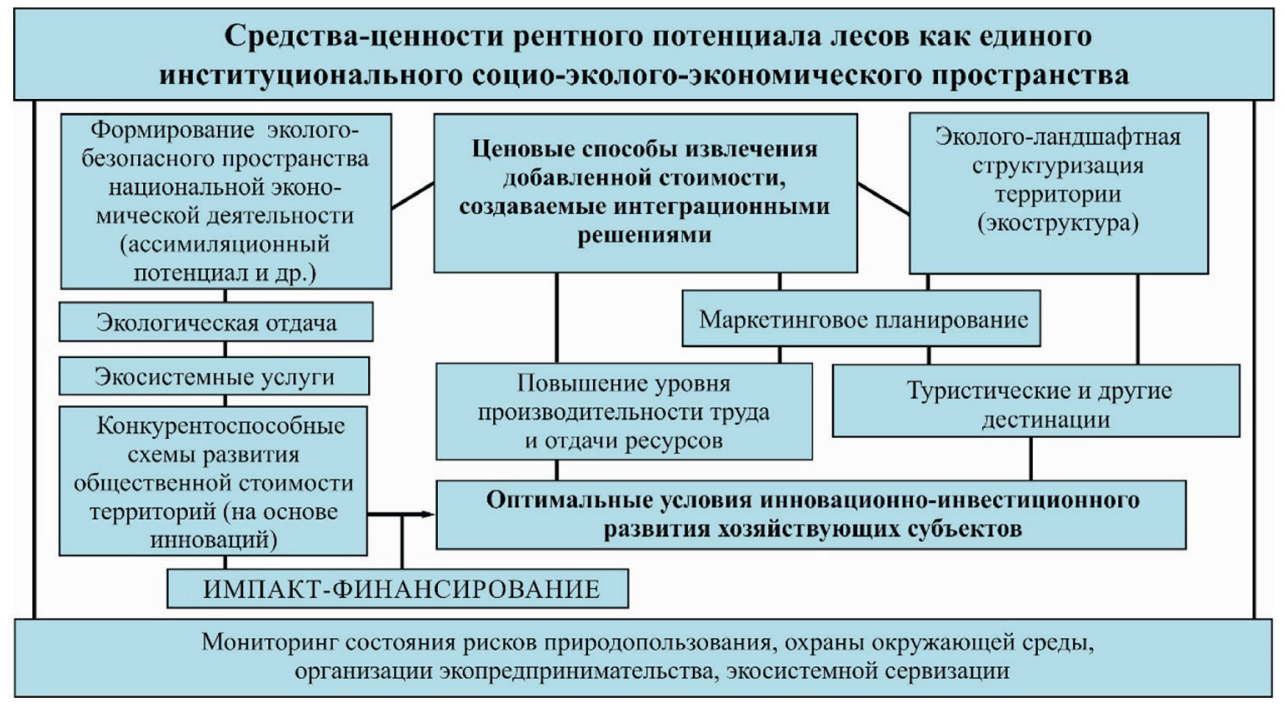

Компоненты рентообразования в аспекте институционального единства социально-эколого-экономического пространства лесов

Components of rent formation in an aspect of institutional unity of socio-ecological and economic space of forests

интеграционными решениями. Посредством ценообразующих практик лесного девелопмента возможными становятся рентно-продуктивные организационно-экономические отношения отраслевых и региональных мезосистем. Представленность в лесном секторе Беларуси неинтериоризированной стоимости лесной ренты обусловливает потребность преобразований экономических отношений через «вычисляемую» информацию, включая результативность импакт-инвестирования в связи с реализацией Целей устойчивого развития. При этом неизбежно совершенствование правил владения-присвоения ренты с учетом динамики инновационной системы прав на рыночную самореализацию экономических агентов, сопровождающуюся развитой системой рычагов государства - стимулирующих, санкционирующих, контролируемых обществом.

Выводы. Особенности и направления развития рентных отношений нами конкретизированы в виде следующих положений:

1) современные рентные отношения опираются не только на системы завоевания рынков (экономику рыночного обмена), но и на различного рода территории рынков и пространства (естественные и искусственные по своему происхождению), в широком (планетарном) аспекте - на созданные социо-эколого-экономические пространства и возможности их эксплуатации в определенных условиях;

2) переход от ренты к стоимости осуществляется и через продукт рынка, и посредством распределения ценностей в пространстве, что обусловливает политический аспект рассмотрения стоимости ренты как управляемой и устойчивой, а это предполагает не столько абсолютизацию прав на часть прибавочной стоимости бизнес-структур, сколько реализацию инновационного поворота (развитие);

3) отслеживание и анализ социально-экологических изменений, инновационного и инклюзивного развития для достижения устойчивого роста экономики выступают в качестве неотъемлемой атрибутики конкурентной (политической) борьбы за пространство в условиях международного соперничества и интеграционных процессов;

4) эксплуатация пространства как объективная причина возникновения экономических (рентных) отношений, через юрисдикцию переходящая в сферу прав, предполагает многоплановые процессы интеллектуализации и информатизации хозяйственных систем (экономику знаний), создающие предпосылки к интеграционным решениям генерации добавленной стоимости и другим средствам-ценностям образования ренты.

Инновационно-социально-экологическая трансформация лесного сектора Беларуси призвана играть важнейшую роль в определении богатства нашей нации и построении устойчивого буду- 
щего на основе рентного механизма управления лесными ресурсами. Кругооборотные процессы рентных отношений в контенте «воспроизводство» предполагают постановку целей формирования управляемой устойчивой стоимости ренты как производной от результатов мониторинга лесного пространства в рамках публичного права, с выходом на контент «адаптация» по конкурентным преимуществам территории государства через возможности идентификации и реальной организации инноваций эколого-ориентированной и устойчивой экономики.

\section{Список использованных источников}

1. Каштелян, Т. В. Проблемы разграничения институциональных сдвигов и оценка перспектив развития лесного сектора Беларуси / Т. В. Каштелян // Изв. Гомел. гос. ун-та им. Ф. Скорины. - 2018. - № 5 (110). - С. $133-139$.

2. Батова, Н. Н. Индекс экологической эффективности как новый индикатор устойчивого развития / Н. Н. Батова // Российская экономика: взгляд в будущее : материалы IV Междунар. науч.-практ. конф. : в 3 ч. / Тамб. гос. ун-т ; отв. ред. Я. Ю. Радюкова. - Тамбов, 2018. - Ч. 1. - С. 205-213.

3. Ciuriak, D. Economic rents and the contours of conflict in the data-driven economy [Electronic resource] / D. Ciuriak. - Waterloo : Centre for Intern. Governance Innovation, 2020. - Mode of access: https://doi.org/10.2307/resrep25327.6. Date of access: 25.09.2020.

4. Frayssé, O. Is the concept of rent relevant to a discussion of surplus value in the digital world? / O. Frayssé // Reconsidering value and labour in the digital age / ed.: E. Fisher, C. Fuchs. - London, 2015. - P. 172-187. https://doi. org/10.1057/9781137478573_10

5. Park, J. Land rent theory revisited / J. Park // Science \& Soc. - 2014. - Vol. 78, № 1 - P. 88-109. https://doi.org/10.1521/ siso.2014.78.1.88

6. Harvey, M. Public or private economies of knowledge: The economics of diffusion and appropriation of bioinformatics tools / M. Harvey, A. McMeekin // Intern. J. of the Commons. - 2010. - Vol. 4, № 1. - P. 481-506. https://doi.org/10.18352/ijc.144

7. Каштелян, Т. В. Особенности рентных отношений в лесном комплексе / Т. В. Каштелян // Тр. БГТУ. Сер. 5 , Экономика и упр. - 2019. - № 1 (220). - С. 41-48.

8. Каштелян, Т. В. Ориентиры воспроизводственных процессов лесного сектора Беларуси в свете теории «переходной» экономики / Т. В. Каштелян // Весн. Магілёўс. дзярж. ун-та імя А. А. Куляшова. Сер. D, Эканоміка, сацыялогія, права. - 2019. - № 1 (53). - С. 32-41.

\section{References}

1. Kashtelyan T. V. Problems of differentiation of institutional shifts in the economy and assessment of prospects for the development of the forest sector in Belarus. Izvestiya Gomel'skogo gosudarstvennogo universiteta imeni F. Skoriny $=$ Proceedings of Francisk Scorina Gomel State University, 2018, no. 5 (110), pp. 133-139 (in Russian).

2. Batova N. N. Environmental performance index as a new indicator of sustainable development. Rossiiskaya ekonomika: vzglyad v budushchee: materialy IV Mezhdunarodnoi nauchno-prakticheskoi konferentsii [Russian economy: a look into the future: materials of the IV International scientific and practical conference]. Tambov, 2018, pt. 1, pp. 205-213 (in Russian).

3. Ciuriak D. Economic rents and the contours of conflict in the data-driven economy. Waterloo, Centre for International Governance Innovation, 2020. Available at: https://doi.org/10.2307/resrep25327.6 (accessed 25.09.2020).

4. Frayssé $\mathrm{O}$. Is the concept of rent relevant to a discussion of surplus value in the digital world? Reconsidering value and labour in the digital age. London, 2015, pp. 172-187. https://doi.org/10.1057/9781137478573_10

5. Park J. Land rent theory revisited. Science \& Society, 2014, vol. 78, no. 1, pp. 88-109. https://doi.org/10.1521/ siso.2014.78.1.88

6. Harvey M., McMeekin A. Public or private economies of knowledge: The economics of diffusion and appropriation of bioinformatics tools. International Journal of the Commons, 2010, vol. 4, no. 1, pp. 481-506. https://doi.org/10.18352/ijc.144

7. Kashtelyan T. V. Features of rental relations in the forest complex. Trudy BGTU. Seriya 5, Ekonomika $i$ upravlenie $=$ Proceedings of BSTU. Issue 5. Economics and Management, 2019, no. 1 (220), pp. 41-48 (in Russian).

8. Kashtelyan T. V. Reference points in reproductive processes of Belarusian forest sector in the light of the "transitional" economy theory. Vesnik Magileuskaga dzyarzhaunaga universiteta imya A.A. Kulyashova. Seryya D, Ekanomika, satsyyalogiya, prava = Mogilev State A. Kuleshov Bulletin. Series D, Economics. Sociology. Law, 2019, no. 1 (53), pp. 32-41 (in Russian).

\section{Информация об авторе}

Каштелян Таисия Васильевна - кандидат экономических наук, доцент кафедры организации производства и экономики недвижимости. Белорусский государственный технологический университет (ул. Свердлова, 13a, 220006, Минск, Республика Беларусь). E-mail: taisiya_kascht@mail.ru

\section{Information about the author}

Taisiya V. Kashtelyan - Ph. D. (Econ.), Associate Professor of the Department of production organization and Real Estate economics. Belarusian State Technological University (13a Sverdlov Str., Minsk 220006, Belarus). E-mail: taisiya_ kascht@mail.ru 